\title{
1. Introduction to a multidisciplinary study of Citizen's Basic Income
}

This introductory chapter introduces the book by exploring the meanings of two of the terms in the book's title and subtitle: 'Citizen's Basic Income' and 'multidisciplinary'.

\section{'CITIZEN'S BASIC INCOME'}

A Citizen's Basic Income is an unconditional income paid to every individual. It is as simple as that. It has a number of different names: Basic Income, Citizen's Income, Citizen's Basic Income, Universal Basic Income. They all mean exactly the same thing: an unconditional income paid to every individual.

The amount that an individual received would not depend on their income, wealth, household structure, employment status, or anything else. Every individual of the same age would receive exactly the same: the same amount, every week or every month, automatically.

Older people might receive more than working age adults, younger adults less, and less for children. Does adjusting the amount with someone's age compromise Citizen's Basic Income's unconditionality? No, it does not. What is unique about Citizen's Basic Income, what matters, and what makes it work, is that it can be turned on at each individual's birth, and turned off at their death, and that no active administration is required in between. Once the computer knows someone's date of birth, it never needs to ask about their age: it can seamlessly adjust the amount paid as the person's age increases. Everyone of the same age would receive exactly the same income, unconditionally.

Sometimes words are added to 'Citizen's Basic Income' or 'Basic Income' - for instance, 'universal', as in 'Universal Basic Income' - but they are not necessary. A Citizen's Basic Income would be unconditional, so within the jurisdiction in which it was paid, everybody would get it, so it would be universal by definition. There would be no need to say that it was. A Citizen's Basic Income would be unconditional, which means that it would not fall if other income rose, so it would be nonwithdrawable. There would be no need to say that it was. It would be universal, and it would be nonwithdrawable, but all we would need to say would be this: Every individual of the same age receives exactly the same income, unconditionally (Torry, 2018b). 
There is no need to say more about the idea of a Citizen's Basic Income at this point. The purpose of the book is to enable a wide variety of disciplines to offer their perspectives, and to say more about the idea at this point would pre-empt that process.

\section{'MULTIDISCIPLINARY'}

The purpose of this book is to study Citizen's Basic Income from the perspectives of a wide variety of academic disciplines, or fields of study. It is 'multidisciplinary', because the different disciplines are employed separately. It attempts not to be 'interdisciplinary': that is, as far as possible it does not employ two or more disciplines at the same time.

Academic disciplines have a history. In the Medieval university, students studied first grammar, logic, and rhetoric, and then arithmetic, music, geometry, and astronomy, and some would go on to study divinity, canon law, civil law, and medicine (University of Cambridge). Then the multiplication began, and it has continued ever since.

To take examples of evolution represented by some of the disciplines on which chapters in this book are based: 'Psychology' evolved from the seventeenth century onwards from denoting the study of the soul to being the study of human behaviour and how the mind works; and since the late nineteenth century, 'social psychology' has studied how, 'given the native propensities and capacities of the human mind, all the complex mental life of societies is shaped by them and in turn reacts upon the course of their development and operation in the individual' (Oxford English Dictionary). Similarly, but in a rather more complex fashion: In the seventeenth century, 'political economy' meant the study of the financial aspects of government, before its meaning was extended in the nineteenth century to mean the study of what became known as 'the economy' as a whole, that is, 'the development and regulation of the material resources of a community or state'; and then the term 'political economy' was displaced by the term 'economics', which had previously meant study of the management of the household before it came to mean 'the branch of knowledge (now regarded as one of the social sciences) that deals with the production, distribution, consumption, and transfer of wealth' (Oxford English Dictionary). Since the 1960s, the term 'political economy' has seen something of a revival: a somewhat chaotic one that has led to it having a rather indeterminate meaning. Following a thorough survey of modern usage of both 'economics' and 'political economy', Groenewegen (1987) concludes that they might best be treated as synonyms, and that their somewhat indeterminate and shifting meanings reflect an important characteristic of the science of economics/political economy. In this book, 'economics' and 'political economy' are not treated as synonyms, as the reader will discover: but the point is well taken 
that to treat them differently is this author's choice from within the possibilities offered by the varying historical and current uses of 'economics' and 'political economy'.

The general point that the above two examples illustrate is that academic disciplines, or fields of study, are social constructions, they evolve over time, and their boundaries and interconnections are fluid. For the sake of the exercise tackled in this book - that is, to understand the different perspectives that different disciplines might offer in relation to the Citizen's Basic Income debate - it has been essential to fix on a working definition of each discipline, because only by doing that can anything like a coherent treatment be offered. Because each discipline has to be understood and then employed in the space of a single chapter, it has also been essential to restrict the sources from which an understanding of each discipline is extracted, so for each chapter a small number of guides to the discipline are chosen. Similarly, within each chapter it has only been possible to offer a restricted number of particular perspectives in relation to an equally restricted number of aspects of the Citizen's Basic Income debate. Because any single aspect of the debate might benefit from perspectives from more than one discipline, and because the disciplines overlap, a certain amount of repetition is inevitable: although an attempt has of course been made to reduce it to a minimum.

The reader will always need to be aware that different choices might have been made: different disciplines might have been selected; different definitions of those disciplines might have been offered; different guides to the disciplines might have been followed; different aspects of the Citizen's Basic Income debate might have been chosen, and they might have been differently allocated to the different chapters; and the perspectives offered in relation to those aspects of the debate might have been different. This, along with space constraints, means that the book cannot claim to be a comprehensive or a definitive collection of perspectives on Citizen's Basic Income. It is a single and necessarily somewhat arbitrary selection of possible perspectives, which means that it might best be seen as an invitation to the reader to undertake their own exercise, by asking what a particular discipline, understood in a particular way, might have to say about a particular aspect of the Citizen's Basic Income debate.

While the main purpose of this book is to ask how a variety of disciplines might contribute to the Citizen's Basic Income debate, a subsidiary outcome might be developments of the disciplines themselves generated by their relationships to that debate. Occasionally such possibilities might be tentatively noted in the conclusions to the chapters. Experts in the different fields of study might be able to propose additional disciplinary developments following their reading of the relevant chapters and their own reflections on the relationship between the Citizen's Basic Income debate and their own areas of expertise. 
In general, readers might wish to regard the omissions and inadequacies of this book - of which there will be many - as invitations to repair them. For instance, where disciplines have not been tackled - for instance, anthropology and social anthropology - experts in those fields might wish to ask how those disciplines might contribute to the Citizen's Basic Income debate, and how that debate might contribute to the development of those disciplines. If historians find the implied definition of Citizen's Basic Income history too narrowly restricted to histories of discussion and activity in relation to genuine Citizen's Basic Incomes, then they might wish to extend the discussion to include histories of such related broader developments as the transition from communal to individual income support, and the evolution of money as a means of exchange and therefore as a means of poor relief and taxation.

This book will have served its purpose if experts from a wide variety of academic disciplines contribute their own understandings of how their disciplines might contribute to the Citizen's Basic Income debate, and of how that debate might contribute to the development of their disciplines.

\section{CONTEXT}

Although Citizen's Basic Income would have the same definition in every country, and its administration would be remarkably similar from country to country, the same cannot be said for existing tax and benefits systems, or for other elements of the contexts within which Citizen's Basic Income schemes might be implemented. Because this book envisages a global readership, most of the material will not make assumptions about existing tax and benefits systems, but will treat them in terms as general as possible. However, where it would be useful to give an example of how a real world tax and benefits system might relate to the implementation of Citizen's Basic Incomes, the UK's system will be employed. This is for two reasons: it is the system with which the author is most familiar; and it contains a large number of different elements, meaning that readers in different countries should be able to find parallels in their own countries' systems. The normal convention will be followed: where a particular kind of benefit or tax is in view, lower case will be used: so 'income tax' means any tax on income, and 'means-tested benefit' means any payment that is adjusted in relation to an individual's or household's existing financial means. However, where a particular UK tax or benefit is being discussed, upper case will be employed: so 'Income Tax' means the UK's income tax, and 'Jobseeker's Allowance' and 'Universal Credit' are two of the UK's means-tested benefits.

A few details about the UK's tax and benefits systems might be helpful: Income Tax is charged on earned and investment income and on some other kinds as well; and National Insurance Contributions are charged 
on earned income. Time-limited and non-means-tested National Insurance benefits are paid for sickness and unemployment on the basis of National Insurance Contributions records (although there is little relationship between the contributions paid and the levels and durations of the benefits awarded); and the amount of someone's Basic State Pension is also based on their National Insurance Contributions Record. A variety of means-tested benefits exist (Jobseeker's Allowance for those out of work, Employment Support Allowance for those who are ill, Working Tax Credits and Child Tax Credits for those in work who are not earning enough to live on, Housing Benefit to help with housing costs, and so on). These are slowly being replaced by the means-tested and work-tested Universal Credit. The one very different benefit is Child Benefit, which is paid unconditionally for every child. (There is now some confusion over this. In 2010, the UK Government said that it wished to means-test Child Benefit for higher earners. This proved to be impossible to achieve: so there is now an additional tax charged on high earning individuals living in households that receive Child Benefit. Child Benefit is still unconditional.) There are also various benefits and services for people living with disabilities; there is an unconditional Winter Fuel Allowance for pensioners; Council Tax Support is a means-tested benefit regulated and administered by Local Authorities; and so on. The system is diverse and complicated.

\section{THE STRUCTURE OF THE BOOK}

Each of the following chapters studies a variety of aspects of the Citizen's Basic Income from the perspective of a particular discipline. First of all the discipline is discussed, generally with the assistance of one or two particular guides; then a number of aspects of the Citizen's Basic Income debate will be studied from the perspective of the discipline; and conclusions will be drawn. Each chapter will end with a case study, except for Chapter 3 about histories of Citizen's Basic Income, because in that chapter the different histories discussed all function as case studies.

Because disciplinary boundaries are fluid and to some extent arbitrary, some fairly arbitrary choices have had to be made. For instance, discussions of both climate change and reciprocity could have been located in Chapter 4 on ethics, but climate change has been located in Chapter 5 on economics (because the discipline of economics might be the best lens for studying the relationship between climate change and Citizen's Basic Income), and reciprocity will be found in Chapter 7 on social psychology (again, because that appears to provide the most useful perspective from which to understand the relationship between Citizen's Basic Income and a society's reciprocity norm). Some disciplines might have been given chapters of their own - for instance, gender studies and theology - but because in the context of the Citizen's Basic Income 
debate the perspectives that they offer fit well within ethical perspectives and sociological perspectives respectively, it is in Chapter 4 that a theological perspective will be found, and in Chapter 8 that a gender perspective is located.

\section{CONCLUSION}

The debate about the radically simple idea of a Citizen's Basic Income is now global, widespread, and deep, and it is time for a book that enables practitioners and theorists from a wide variety of disciplines to ponder the contribution that their own and other disciplines might make to that debate. This book sets an agenda in the hope that others will contribute to it. 